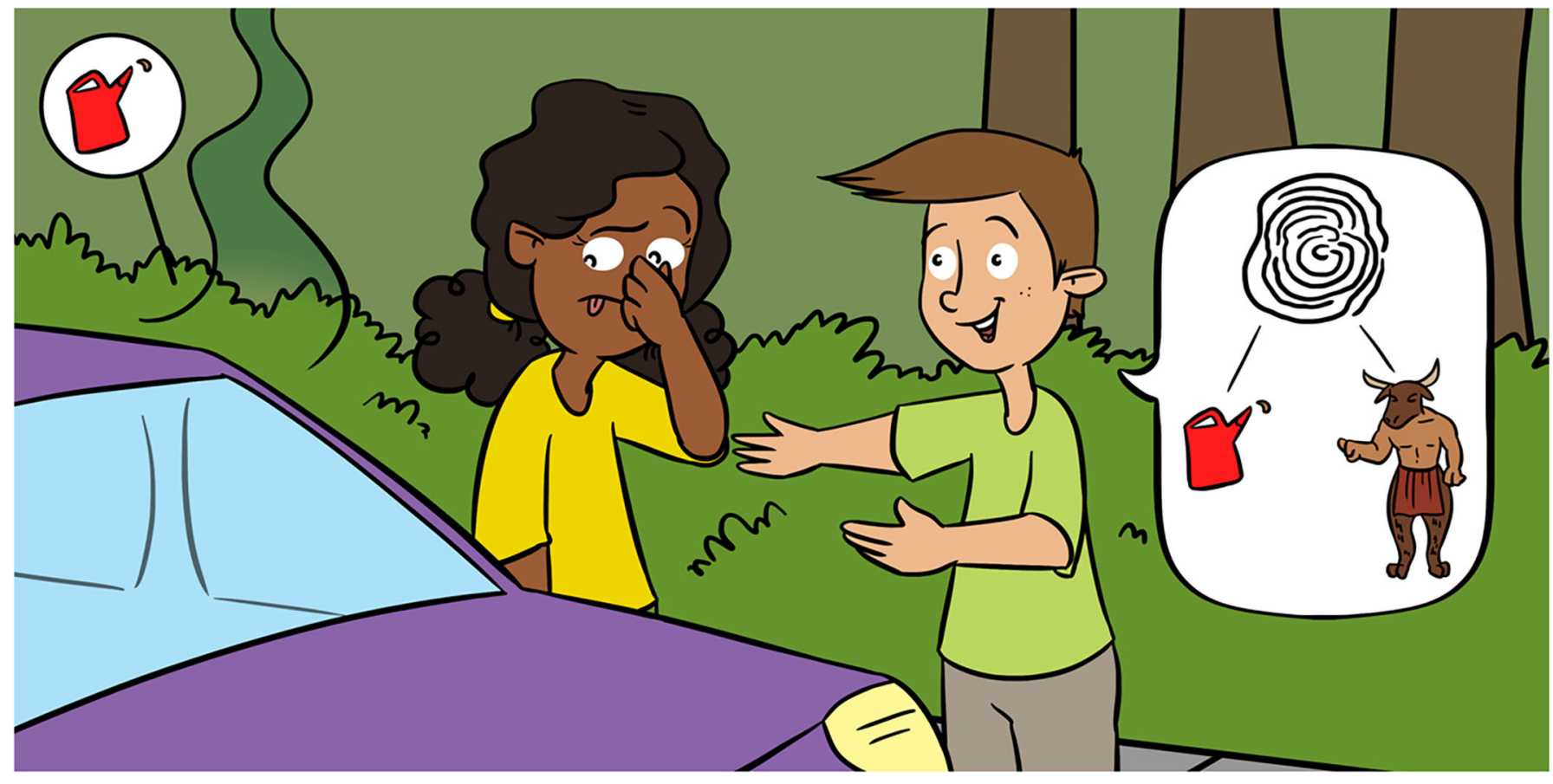

\title{
A MYTHIC LABYRINTH INSIDE YOUR VEHICLE PREVENTS GASOLINE LEAKAGE
}

\section{Joel Gutiérrez-Martínez * and Nguyen Esmeralda López-Lozano}

División de Ciencias Ambientales, Instituto Potosino de Investigación Científica y Tecnológica (IPICYT), San Luis Potosí, Mexico

YOUNG REVIEWERS:

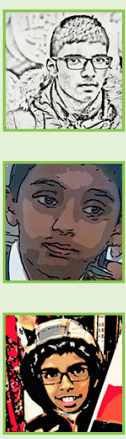

ELILL

AGE: 14

SASYAK

AGE: 13

YUHENDRA

AGE: 11
It is hard to believe that our vehicles can contaminate the environment even when they are not running. This is a consequence of evaporated gasoline leaking from a vehicle's fuel tank into the atmosphere. To avoid this leakage, evaporated gasoline is vented to a canister packed with charcoal particles called activated carbon. There are deep, channel-like spaces inside activated carbon where gasoline molecules are adsorbed. Adsorption is a process in which molecules of gas or liquid stick to the surface of something solid. Through adsorption it is possible to remove various pollutants from air and water. To understand how adsorption by activated carbon works, picture activated carbon as a maze that traps the gasoline particles and does not let them escape. Finally, we describe current efforts to develop new adsorbing materials from the waste product of another industry, to improve upon the activated carbon currently used in vehicles. 
Figure 1

Even when a vehicle is not running,

evaporated gasoline can escape from the fuel tank into the environment. These evaporative emissions contain molecules called volatile organic compounds, which can harm the environment.

\section{EVAPORATIVE \\ EMISSIONS}

The evaporated gasoline that escapes from the fuel tank and is an important source environmental pollution with VOCs.

\section{VOLATILE ORGANIC COMPOUNDS (VOCs)}

Molecules that readily change from liquid to gas at room temperature. VOCs are used in the manufacturing of paints,

pharmaceuticals, cleaning agents, and other products.

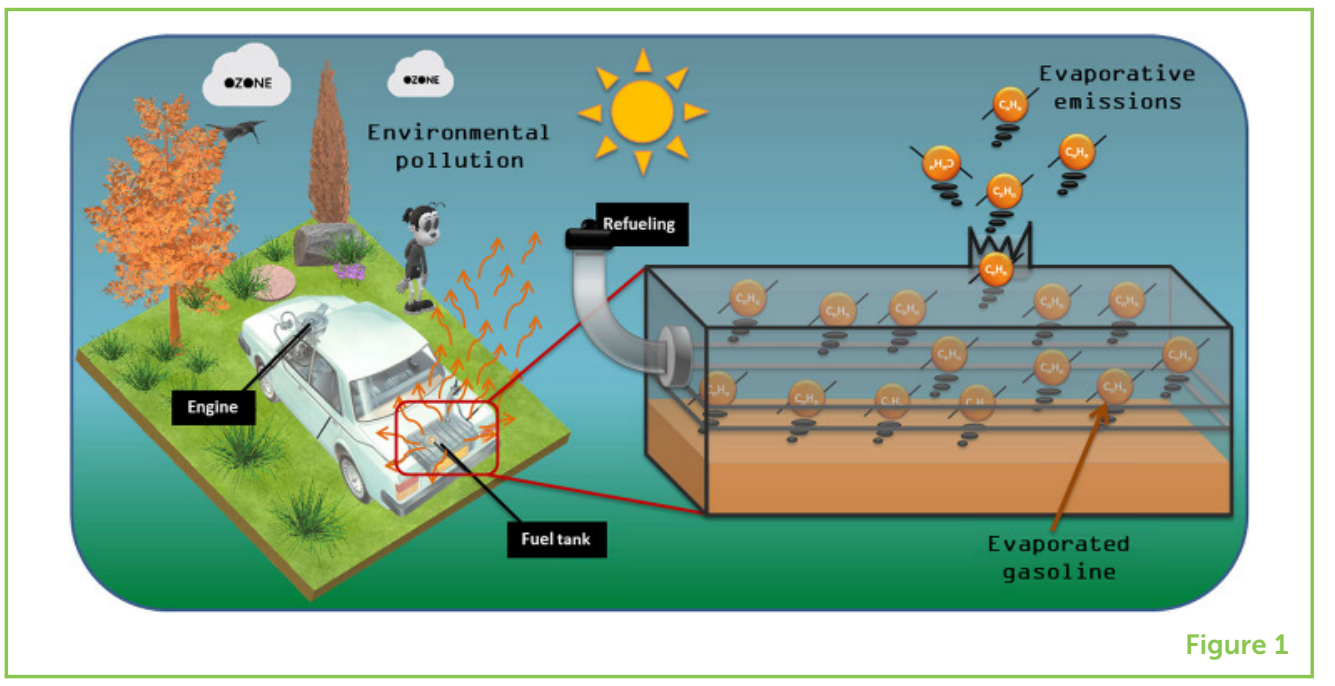

\section{WHY DOES GASOLINE TRY TO ESCAPE FROM VEHICLES?}

It is certainly known that vehicles pollute when their engines are working. This pollution is a consequence of the greenhouse gases emitted through the vehicle's tailpipe. In older vehicles, these emissions often look like black smog. But did you know that vehicles can pollute even when they are not running? This is because the gasoline stored in the fuel tank can escape from the vehicle directly into the environment, polluting the atmosphere.

On a warm day, it is quite common to smell gasoline near a parked vehicle. This is because gasoline is volatile, which means that it can change from liquid to gas even when it is not at its boiling temperature, and therefore it can pass into the air. When the outdoor temperature increases, the movement of gasoline molecules in a car's fuel tank increases rapidly in all directions, expanding its volume. If it's warm enough, the volatile molecules can acquire enough energy to escape through the fuel tank gaskets into the environment [1]. Evaporated gasoline that manages to escape is known as evaporative emissions (Figure 1).

Gasoline is a mixture of volatile molecules with different sizes and forms, mainly composed of carbon (C) and hydrogen (H) atoms. The most volatile molecules include butane $\left(\mathrm{C}_{4} \mathrm{H}_{10}\right)$ and pentane $\left(\mathrm{C}_{5} \mathrm{H}_{12}\right)$. It is also common to find benzene $\left(\mathrm{C}_{6} \mathrm{H}_{6}\right)$ and toluene $\left(\mathrm{C}_{7} \mathrm{H}_{8}\right)$ in gasoline [2]. All these molecules are called volatile organic compounds (VOCs), and they are harmful to human health and contribute to climate change [3]. In fact, evaporative emissions of VOCs contribute to half of the worldwide VOC pollution of the atmosphere.

To avoid the leakage of volatile gasoline molecules from a vehicle into the environment, the fuel tank is connected to a device known as a canister, which is located between the vehicle's fuel tank and 
the engine (Figure 2). The canister captures the gasoline molecules in a maze of carbon molecules. To explain how this labyrinth prevents gasoline molecules from escaping into the environment, the famous Greek tale of the Minotaur labyrinth is a great analogy.

\section{HOW DOES A CANISTER RESEMBLE THE MINOTAUR LABYRINTH?}

Labyrinths are complex structures designed so that people cannot escape from them. One of the most legendary labyrinths is the mythological labyrinth of the Minotaur. This labyrinth was an enormous, impressive construction made by the famous architect Daedalus on the Island of Crete, in the middle of the Aegean Sea. According to this mythic tale, Daedalus constructed the labyrinth to hide the Minotaur, a creature half man and half bull. Every seven years, a black ship sailed with young Greeks trying to escape from Athens to Crete. When the ship arrived at the island of Crete, the young Greeks were led into the labyrinth, where they got lost in the passages. Suddenly, the Minotaur would emerge from the passages to chase the Greeks and satisfy its thirst for blood (Figure 2A). As strange as it may sound, this tale is a suitable analogy to explain how a canister packed with activated carbon works.

The United States Environmental Protection Agency requires that modern vehicles are equipped with a canister to stop evaporative emissions (Figure 2B). The canister is packed with particles of activated carbon. Activated carbon is a charcoal material widely used in purification of drinking water and natural gas, or for purifying the water in a fish tank. Activated carbon is used in these canisters because of its low cost and because it can capture a lot of volatile molecules. On the molecular level, activated carbon is a solid material made of carbon atoms linked together to form hexagonal ring structures, which extend into multiple sheets called graphene layers [4]. If we look inside activated carbon, we can see internal channels, called pores, which resemble the passages of a labyrinth. The walls of these pores are built of stacked graphene layers (Figure 2C). In this sense, the pollutants, such as gasoline emissions, will enter activated carbon labyrinth through these pores and they will remain stuck on graphene layers.

Vehicles are constructed so that VOCs that evaporate from the gasoline in the fuel tank are directed from the fuel tank through a hose to the canister. The VOCs, like the young Greeks, are led toward a labyrinth. Those that enter the labyrinth are gradually lost within its passages. As gasoline molecules go deeper into the labyrinth, the passages become narrower. The wandering VOCs soon become stuck to the walls of this labyrinth, in a process called adsorption. Activated carbon and VOCs are attracted to each other like magnets. The adsorption process occurs even when the vehicle is not running. 
Figure 2

The adsorption of evaporated gasoline on activated carbon can be compared to the Labyrinth of the Minotaur. (A) Greeks arrived on Crete to wander through a labyrinth until they were eaten by the Minotaur. (B)

Evaporated gasoline $\left(\mathrm{C}_{n} \mathrm{H}_{\mathrm{n}}\right)$ is vented to a canister where the molecules become "lost" and adsorbed, then desorbed when the vehicle is running, to be burned in the engine. (C) Adsorption of gasoline molecules occurs on passage walls made of activated carbon, which is made of carbon atoms linked together to form graphene sheets.

\section{DESORPTION}

The opposite process of adsorption, in which molecules are released from a surface.

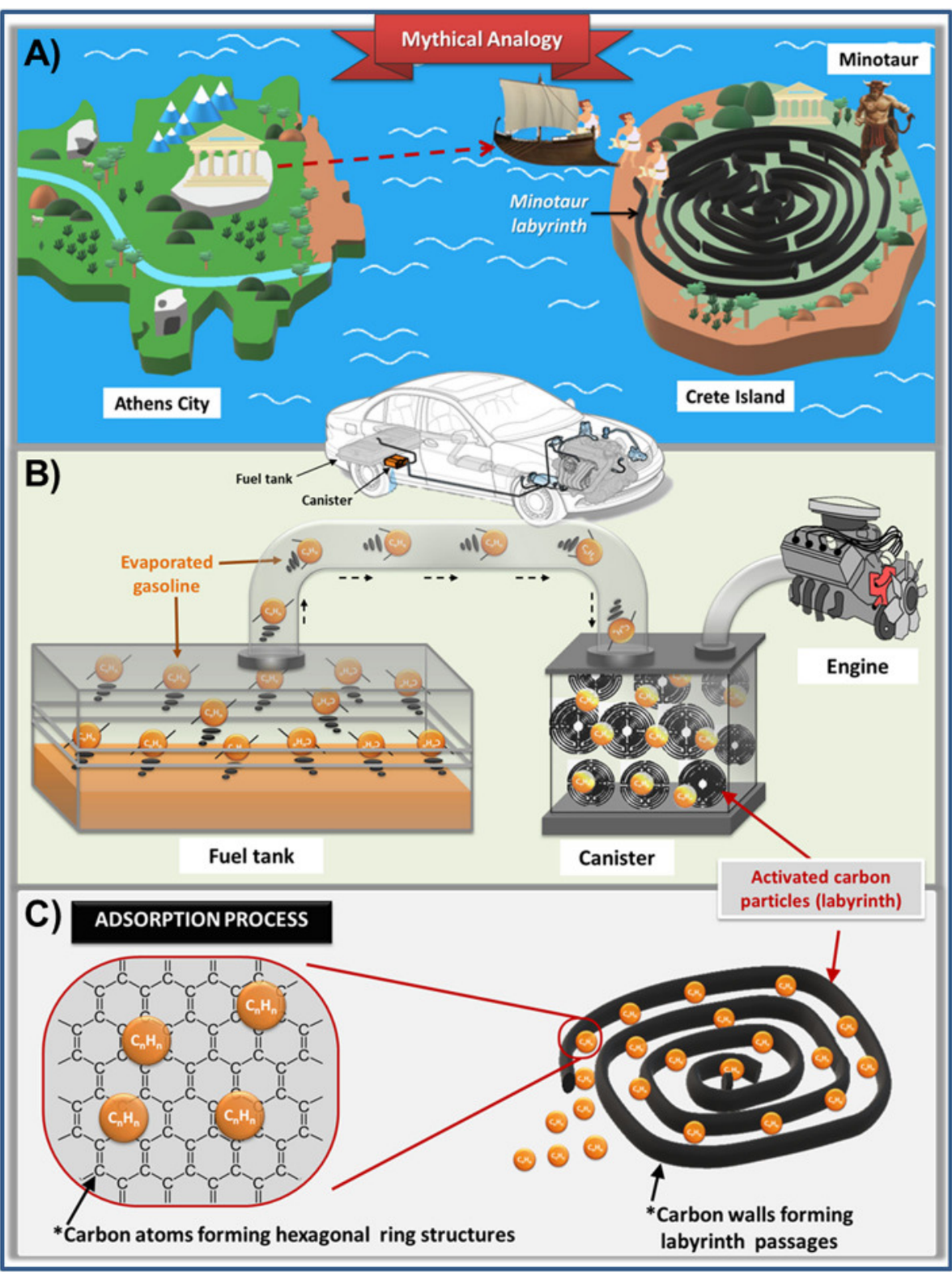

Figure 2

Continuing with this analogy, the labyrinth passages must be cleaned so that they can adsorb new VOCs the next day. For this reason, the vehicle's engine acts as the Minotaur, by feeding on the VOCs. The next time the vehicle is started, air is passed through the canister to separate VOCs from the walls of the activated carbon passages. This process is called desorption, which means unsticking the molecules that are adsorbed to the passages. These desorbed molecules are then burned in the engine. At this point, the activated carbon passages have been cleaned and the canister is ready to absorb VOCs again. The adsorption and reuse of evaporated gasoline not only help to prevent VOCs from entering the environment, but also help vehicles to use fuel more efficiently, which saves money. 


\section{CAN THE PERFORMANCE OF THE LABYRINTH BE IMPROVED?}

According to the Greek tale, Daedalus identified a problem with the labyrinth. Some of the Greeks trapped in the labyrinth managed to escape at nightfall. Based on this problem, Daedalus improved the labyrinth to trap the Greeks more efficiently. The new labyrinth allowed the Minotaur to find the Greeks more easily. Activated carbon has a similar disadvantage, despite its high capacity to adsorb VOCs. In the very narrow passages of activated carbon, VOCs are strongly adsorbed to the graphene layers and even if they achieve to get desorbed from the narrowest passages when the vehicle is started, some VOCs may not get to escape from the labyrinth. These VOCs could then slowly escape into the environment when vehicle is not running. Although only few VOCs manage to escape, this is still an environmental problem. For this reason, scientists are focused on improving the performance of the canister by synthesizing new labyrinths made of carbon.

Currently, our research group is working on the development of new carbon labyrinths. To prevent evaporative emissions, the passages of the new labyrinth must be wide enough to rapidly adsorb gasoline molecules, and the molecules must be completely desorbed when the car is running, to clean the passages. In addition, what if we could reuse waste materials from another industry to produce these labyrinths? The tequila industry in Mexico generates thousands of tons of waste each year. Tequila (an alcoholic drink) is made by extracting a substance from the agave plant. The rest of the plant becomes waste called agave bagasse. Disposal of so much agave bagasse is an environmental problem. Fortunately, we have processed agave bagasse to develop a new labyrinth, by heating it to $500^{\circ} \mathrm{C}$, which produces a new material. This new material is commonly known as biochar since it is a carbon-based material like charcoal (activated carbon). This new labyrinth has wide pores and large passages throughout the material (Figure 3). Since it is similar to activated carbon, VOCs from gasoline are strongly adsorbed, and the wide pores and passages are ideal for complete desorption. This helps to prevent VOCs from escaping into the environment when the vehicle is turned off again [5].

It is possible to further improve the adsorption capacity of this new labyrinth! The strategy is to build pillar-shaped structures, like columns, throughout the large passages of the labyrinth. In scientific terms, these pillars are known as carbon nanotubes. Carbon nanotubes are tiny cylindrical structures made primarily of carbon atoms (Figure 3). The addition of carbon nanotubes to the biochar passages increases the capacity of biochar to adsorb VOCs.

The production of carbon labyrinths from agave bagasse shows how a waste material can be of interest to the automotive industry and 
Figure 3

Synthesis of a novel adsorbent material from a waste product. Large amounts of agave bagasse are produced by the tequila industry. This waste product can be burned at high temperatures to create biochar, which is similar to activated carbon but has wider passages. To further improve the ability of biochar to adsorb VOCs, carbon nanotubes can be grown on its wide passages. These can be seen through a powerful microscope called a scanning electron microscope.

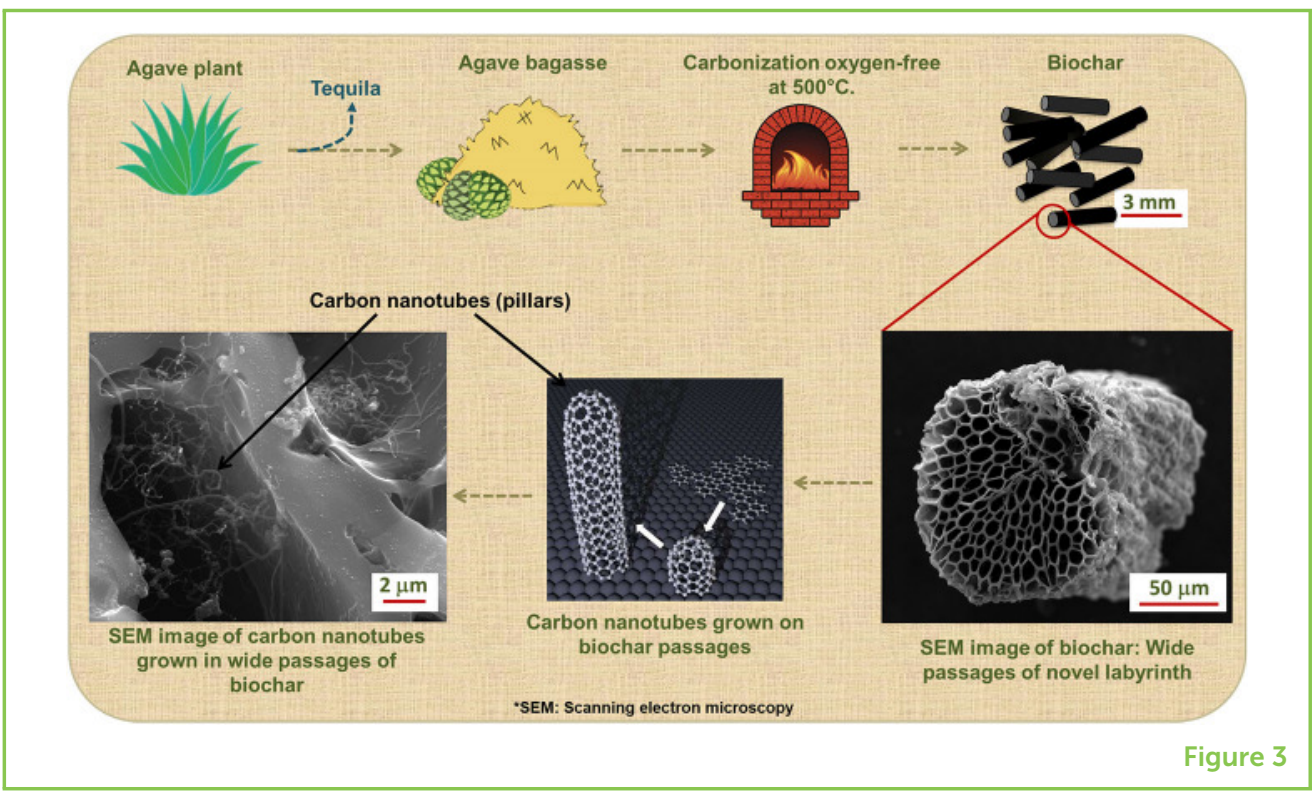

possibly other industries. The main advantages are that the agave bagasse is free and the processing is environmentally friendly. In addition, structures such as carbon nanotubes allow improving the performance of these labyrinths. However, not all the pollutants in gasoline can be adsorbed by the same material. Therefore, each pollutant may require a specific labyrinth with different characteristics. Fortunately, the scientific community is focusing its efforts on developing new labyrinths that can eliminate specific pollutants. Canister made with such labyrinths will hopefully be even better at protecting the environment from VOCs.

\section{CARBON LABYRINTHS HELP THE ENVIRONMENT}

Finally, it is important to highlight that the adsorption process is used for many different applications, including the removal of VOCs from industrial chimneys. Adsorption can also remove pollutants such as arsenic and fluoride from drinking water in countries where these contaminants are a problem. Additionally, adsorption can be used after a catastrophic oil spill, like the one in the Gulf of Mexico in 2010 to remove the dangerous oil components that may dissolve in the water. The adsorption process is also being used to remove $\mathrm{CO}_{2}$ from the air, for later use in greenhouses. This last application is of growing interest, because the increasing $\mathrm{CO}_{2}$ in the atmosphere is an important cause of climate change. Overall, you can see that there are many important uses for labyrinth-like materials! Solids that can adsorb environmental pollutants from water or air are an excellent addition to our collection of resources that will help us to protect the earth from the harm caused by many human activities. 


\section{REFERENCES}

1. Mirzaei, A., Leonardi, S. G., and Neri, G. 2016. Detection of hazardous volatile organic compounds (VOCs) by metal oxide nanostructures-based gas sensors: a review. Ceram. Int. 42:15119-41. doi: 10.1016/j.ceramint.2016.06.145

2. Jia, L., Yu, W., Long, C., and Li, A. 2014. Adsorption equilibrium and dynamics of gasoline vapors onto polymeric adsorbents. Environ. Sci. Pollut. Res. 21:3756-63. doi: 10.1007/s11356-013-2328-z

3. Li, B., Sai, S., Ho, H., Xue, Y., Huang, Y., and Wang, L. 2017. Characterizations of volatile organic compounds (VOCs) from vehicular emissions at roadside environment : the fi rst comprehensive study in Northwestern China. Atmos. Environ. 161:1-12. doi: 10.1016/j.atmosenv.2017.04.029

4. Goyal, M., and Bansal, R. C. 2005. Activated Carbon Adsorption. Boca Raton, FL: Taylor \& Francis Group.

5. Nieto-Delgado, C., and Rangel-Mendez, J. R. 2011. Production of activated carbon from organic by-products from the alcoholic beverage industry: surface area and hardness optimization by using the response surface methodology. Ind. Crops Prod. 34:1528-37. doi: 10.1016/j.indcrop.2011.05.014

SUBMITTED: 19 May 2020; ACCEPTED: 06 September 2021; PUBLISHED ONLINE: 05 October 2021.

EDITED BY: Noemie Ott, Swiss Federal Laboratories for Materials Science and Technology, Switzerland

CITATION: Gutiérrez-Martínez J and López-Lozano NE (2021) A Mythic Labyrinth Inside Your Vehicle Prevents Gasoline Leakage. Front. Young Minds 9:563843. doi: $10.3389 /$ frym.2021.563843

CONFLICT OF INTEREST: The authors declare that the research was conducted in the absence of any commercial or financial relationships that could be construed as a potential conflict of interest.

COPYRIGHT @ 2021 Gutiérrez-Martínez and López-Lozano. This is an open-access article distributed under the terms of the Creative Commons Attribution License (CC BY). The use, distribution or reproduction in other forums is permitted, provided the original author(s) and the copyright owner(s) are credited and that the original publication in this journal is cited, in accordance with accepted academic practice. No use, distribution or reproduction is permitted which does not comply with these terms.

\section{YOUNG REVIEWERS}

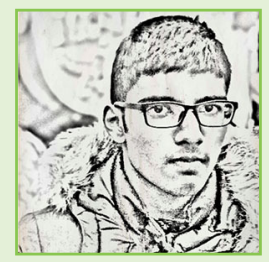

\section{ELILL, AGE: 14}

Hi! My name is Elill and I am 15 years old. I like reading non-fiction books, studying and spending time with family. My favorite subjects in school are Science, History, and Maths. 

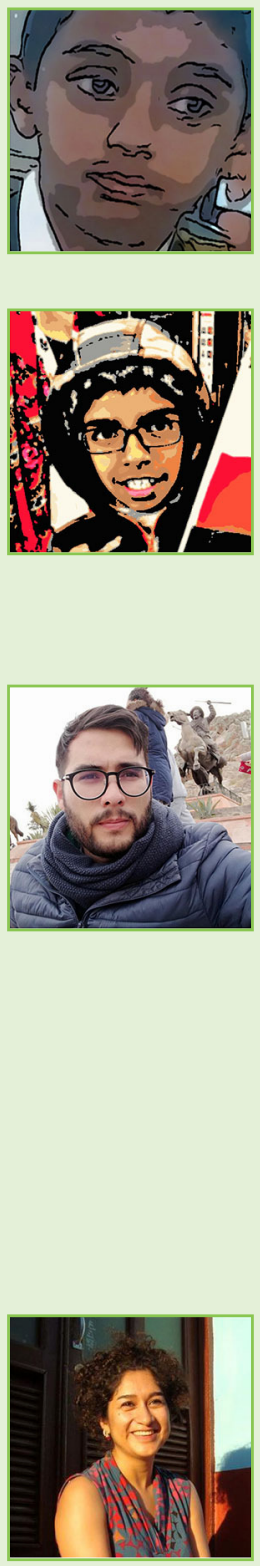

\section{SASYAK, AGE: 13}

Sasyak is a 13 year old student from India. He is an avid reader of several genres of books. He is a keen participant in quiz contests and olympiads, and is a spell bee champion. He attends football classes and enjoys cycling.

\section{YUHENDRA, AGE: 11}

$\mathrm{Hi}$ ! It is great to be a reviewer. I am 11 years old and I like science and Maths. They are my favorite subjects at school. As a past time I do lego read books and spend time with my family. I also like to play video games.

\section{AUTHORS}

\section{JOEL GUTIÉRREZ-MARTÍNEZ}

I am a biochemical engineer from the Autonomous University of Aguascalientes. I obtained my master's degree at the Potosino Institute for Scientific and Technological Research (IPICyT), in Mexico. Currently, I am studying for my Ph.D. in the Environmental Science Department at IPICYT. I am focused on carbon materials and adsorption processes. I have experience in manufacturing carbon-based materials such as activated carbons and carbon nanotubes. Also, I have been involved in adsorption projects to remove pollutants from groundwater with activated carbon. Currently, I am involved in using the adsorption process to remove pollutants from the air. In addition to my research skills, I am currently interested in reading about history and mythology, especially from ancient Greece. *joel.gutierrez@ipicyt.edu.mx

\section{NGUYEN ESMERALDA LÓPEZ-LOZANO}

I am biologist, with a master's degree in biochemical sciences and a Ph.D. in biomedical sciences. Currently, I work as a researcher in the Environmental Science Division of IPICyT. My field of study is the relationship of microorganisms with one another and with their environment, particularly in water-scarce. I am also a fan of science outreach. 